\title{
JOURNAL OF \\ NEUROPHYSIOLOGY
}

March 1993

Volume 69, Number 3

The Spinal Gf

Coordination i

J. Teg

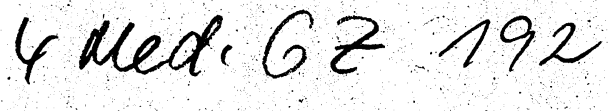

tors

Responses of $₫$

Mutual Suppre

M. B.

The Morpholo

A. S. $F$

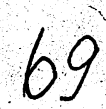

647

658

$\operatorname{lgg} 3$

2

669

$\mathrm{GABA}_{\mathrm{B}}$ Autor

Signal Transm:

$$
7 \sqrt{3}-1749
$$

D. D.

Passive Current Flow and Morphology in the Terminal Arborizations of the

Posterior Pituitary

M. B. Jackson

Wide Dynamic Range but not Nociceptive-Specific Neurons Encode

Multidimensional Features of Prolonged Repetitive Heat Pain

R. C. Coghill, D. J. Mayer, and D. D. Price

Facilitation and Delayed Release at About $0^{\circ} \mathrm{C}$ at the Frog Neuromuscular Junction:

Effects of Calcium Chelators, Calcium Transport Inhibitors, and Okadaic Acid

W. Van der Kloot and J. Molgó

Responses of the Starburst Amacrine Cells to Moving Stimuli

D. M. O'Malley and R. H. Masland

Thalamic VPM Nucleus in the Behaving Monkey. I. Multimodal and Discriminative Properties of Thermosensitive Neurons

M. C. Bushnell, G. H. Duncan, and N. Tremblay

Thalamic VPM Nucleus in the Behaving Monkey. II. Response to Air-Puff

Stimulation During Discrimination and Attention Tasks

N. Tremblay, M. C. Bushnell, and G. H. Duncan

Opponent Effects of Potassium on $\mathrm{GABA}_{\mathbf{A}}$-Mediated Postsynaptic Inhibition in the

Rat Hippocampus

M. S. Jensen, E. Cherubini, and Y. Yaari

Contribution of the Monkey Corticomotoneuronal System to the Control of Force in Precision Grip

M. A. Maier, K. M. B. Bennett, M.-C. Hepp-Reymond, and R. N. Lemon

Smooth Eye Movements Elicited by Microstimulation in the Primate Frontal Eye Field

J. P. Gottlieb, C. J. Bruce, and M. G. MacAvoy

Effect of Eye Position Within the Orbit on Electrically Elicited Saccadic Eye Movements: A Comparison of the Macaque Monkey's Frontal and Supplementary Eye Fields

G. S. Russo and C. J. Bruce 
Ion Channels in Spinal Cord Astrocytes In Vitro. III. Modulation of Channel Expression by Coculture With Neurons and Neuron-Conditioned Medium

C. L. Thio, S. G. Waxman, and H. Sontheimer

Enduring Alterations in Neurophysiological Taste Responses After Early Dietary

Sodium Deprivation

M. B. Vogt and D. L. Hill

Response Properties of Single Units i the the Lateral Lemniscus and Paralemniscal Zone of an Echolфcatinigegaitàts-

E. Covey

Bibliothek

842

Effect of Cytoplasmic Chloride Condentration on Open-State Preference of Glycine-

Activated Chloride Channels in Cultured Spinal Cord Cells

A. I. McNiven and A. R. Martin

860

Characterization of Responses of $T_{2}-T_{4}$ Spinal Cord Neurons to Esophageal

Distension in the Rat

I. Euchner-Wamser, J. N. Sengupta, G. F. Gebhart, and S. T. Meller

868

Ionic Currents in Giant Motor Axons of the Jellyfish, Aglantha digitale

R. W. Meech and G. O. Mackie

Potassium Channel Family in Giant Motor Axons of Aglantha digitale

R. W. Meech and G. O. Mackie

Ventral Intraparietal Area of the Macaque: Anatomic Location and Visual

Response Properties

C. L. Colby, J.-R. Duhamel, and M. E. Goldberg

902

A Molecularly Defined Cardiorespiratory Interneuron Expressing SDPFLRFamide/ GDPFLRFamide in the Snail Lymnaea: Monosynaptic Connections and Pharmacology

D. R. Skingsley, K. Bright, N. Santama, J. van Minnen, M. J. Brierley,

J. F. Burke, and P. R. Benjamin

Peptide Modulation of ACh Receptor Desensitization Controls Neurotransmitter Release From Chicken Sympathetic Neurons

D. C. Valenta, J. E. G. Downing, and L. W. Role

Nonlinear Stretch Reflex Interaction During Cocontraction

R. R. Carter, P. E. Crago, and P. H. Gorman

Effects of Low-Frequency Stimulation of the Superior Colliculus on Spontaneous and Visually Guided Saccades

P. W. Glimcher and D. L. Sparks

Monkey Superior Colliculus Represents Rapid Eye Movements in a Two-

Dimensional Motor Map

K. Hepp, A. J. Van Opstal, D. Straumann, B. J. M. Hess, and V. Henn

Parametric Modeling of the Temporal Dynamics of Neuronal Responses Using Connectionist Architectures

S. C. Bankes and D. Margoliash

\section{RAPID PUBLICATIONS}

Dynamic Clamp: Computer-Generated Conductances in Real Neurons A. A. Sharp, M. B. O'Neil, L. F. Abbott, and E. Marder 


\title{
Bilateral Inhibition by Glycinergic Afferents in the Medial Superior Olive
}

\author{
BENEDIKT GROTHE AND DAN H. SANES \\ Zoologisches Institut der Universität München, 8000 Munich 2, Germany; and the Center for Neural Science; \\ and Department of Biology, New York University, New York, New York 10003
}

\section{SUMMARY AND CONCLUSIONS}

1. Coincidence-detection of excitatory synaptic potentials has long been considered to be the mechanism by which medial superior olivary (MSO) neurons compute interaural time differences. Here we demonstrate the contribution of synaptic inhibition in this circuit using a gerbil brain slice preparation.

2. Nearly all cells exhibited excitatory postsynaptic potentials (EPSPs) and action potentials (APs) after stimulation of either the ipsilateral or contralateral afferent pathway. In $44 \%$ of cells, the latency of APs depended on stimulus amplitude, exhibiting shifts of $0.25-2 \mathrm{~ms}$.

3. Nearly all neurons ( $89 \%$ ) exhibited stimulus-evoked synaptic inhibition. The inhibitory effects were enhanced at greater stimulus amplitudes and were usually able to block synaptically evoked APs. In addition, APs and EPSPs were reversibly blocked by delivering the inhibitory transmitter glycine in almost all tested cells $(91 \%)$.

4 . In the presence of the glycine antagonist strychnine, the effects of synaptic inhibition were suppressed.

5. The stimulus level-dependent inhibitory potentials influenced the probability that an MSO neuron would fire an AP, as well as the precise timing. Therefore, the present results have implications for the processing of interaural time differences by the MSO and at higher auditory centers.

\section{INTRODUCTION}

The medial superior olivary (MSO) nucleus has been considered the primary site for processing interaural time differences (ITDs) by coincidence-detection of synaptic excitation (Casseday and Neff 1973; Jeffress 1948; Jenkins and Masterton 1982). The supporting data include converging afferents from both cochlear nuclei (Goldberg and Brown 1968; Stotler 1953; Warr 1966), with identical types of synapses from either side (Clark 1969; Perkins 1973) and a majority of neurons that are excited by sound stimulation of either ear (Caird and Klinke 1983; Goldberg and Brown 1969; Langford 1984; Yin and Chan 1990).

Anatomic results now suggest that MSO does receive inhibitory afferents, mainly from the ipsilateral medial nucleus of the trapezoid body (MNTB; Grothe et al. 1992; Kuwabara and Zook 1991; Spangler et al. 1985). The MNTB is known to provide glycinergic inhibition to neurons in the lateral superior olive (LSO; Moore and Caspary 1983; Sanes et al. 1987; Wu and Kelly 1992). There is also a second presumed inhibitory projection to MSO neurons from the lateral nucleus of the trapezoid body (LNTB; Cant and Hyson 1992).

Goldberg and Brown (1969) demonstrated a decrease of the MSO neuron response at certain interaural phase disparities similar to that shown previously in the inferior colliculus (Rose et al. 1966). This and other response properties of cat MSO neurons were recently studied in great detail by Yin and Chan (1990). In such cases, the number of spikes drops below the level due to monaural stimulation and, in some cases, even below the spontaneous activity level. The out-of-phase inhibition could be due to time-sensitive inhibitory projections, analagous to the ITD-sensitive excitatory-inhibitory (EI) and inhibitory-excitatory (IE) neurons in the auditory brain stem (Goldberg and Brown 1969; Hall 1965; Harnischfeger et al. 1985). However, Colburn et al. (1990) have presented a mathematical model that is able to explain this out-of-phase inhibition in MSO neurons without any inhibitory inputs. For example, noninhibitory mechanisms such as $\mathrm{Na}^{+}$inactivation could also contribute to a suppression of discharge (Hodgin and Huxley 1952). Thus the role of inhibition for ITD coding within the MSO remains unclear.

A functional description of inhibitory interactions within the MSO has been obtained in the mustached bat. The MSO in this species clearly has a different function than ITD detection because of a reduced projection from the ipsilateral ventral cochlear nucleus, leading to an MSO with predominantly monaural properties. There is a profound effect of glycinergic inhibition on the temporal properties of MSO neurons in this species (Covey et al. 1991; Grothe 1990; Grothe et al. 1992).

In the present study, we investigated synaptic integration by MSO neurons with intracellular recordings obtained from a gerbil brain slice preparation to determine the impact of synaptic inhibition.

\section{MATERIALS AND METHODS}

The methods used were previously described in some detail (Sanes 1990). Briefly, gerbils (Meriones unguiculatus) aged 1725 days postnatal were anesthetized with chloral hydrate (400$500 \mathrm{mg} / \mathrm{kg}$ ip) and decapitated. The brain was rapidly dissected free in an oxygenated artificial cerebrospinal fluid (ACSF) at $15^{\circ} \mathrm{C}$ and vibratome sectioned at $350-400 \mu \mathrm{m}$.

For recordings, the slices were placed in a custom chamber and perfused with oxygenated $\operatorname{ACSF}\left(8 \mathrm{ml} / \mathrm{min} ; 31^{\circ} \mathrm{C}\right)$. Electric stimuli were delivered with two bipolar stimulating electrodes positioned lateral to the LSO (ipsilateral pathway) and medial to the MNTB, near the midline (contralateral pathway). Stimuli were presented manually (Grass Instruments S11) with bipolar Tefloncoated platinum electrodes or under computer control (RC Elec- 


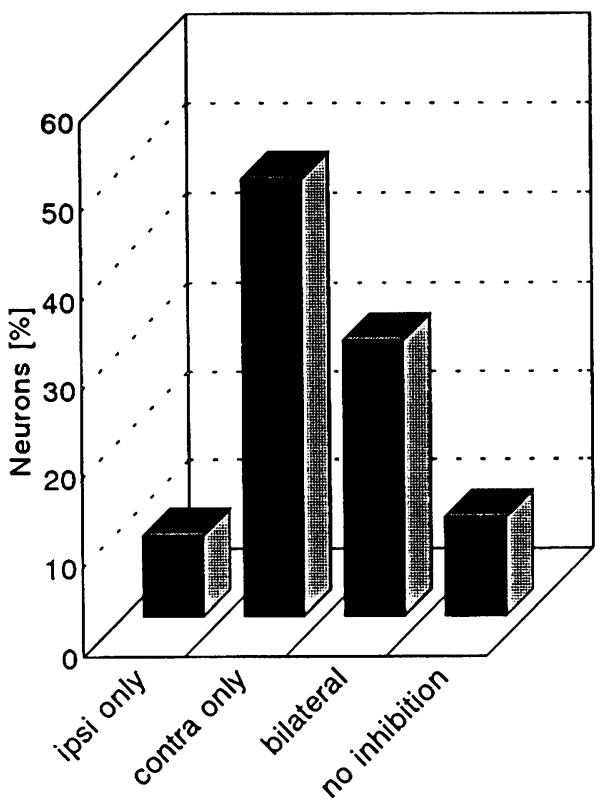

FIG. 1. Distribution of inhibitory postsynaptic potentials (IPSPs) in the gerbil medial superior olive (MSO) in the brain slice preparation $(n=$ 80 ). Notice that only $11 \%$ of tested neurons failed to exhibit inhibition.

tronics; Everex 386). The stimuli consisted of $100-\mu$ s pulses at $0-65 \mathrm{~V}$.

Intracellular recordings were obtained with glass electrodes filled with $2 \mathrm{M}$ potassium citrate and having a resistance of 130$200 \mathrm{M} \Omega$. The voltage signals (Axoprobe 1-A) were digitized (ComputerBoards) and stored for off-line analyses. Electrodes were positioned in the MSO cell body region under visual control. Recordings could rarely be obtained outside of this region. The mean resting potential for all analyzed neurons was $-56 \pm 4$ (SD) $\mathrm{mV}(n=80)$.

Glycine, $\gamma$-aminobutyric acid (GABA), and strychnine were prepared at relatively high concentrations (50-100 mM), and small volumes $(5-200 \mu \mathrm{l})$ were added to the superfusate in advance of the recording well. A minimum effective dosage was rapidly ascertained by adding small aliquots, thus assuring that each agent could be washed out as rapidly as possible.

\section{RESULTS}

The vast majority of MSO neurons ( $89 \% ; n=80)$ exhibited synaptic inhibition. These responses were evoked with exclusively contralateral stimulation in $49 \%$ of neurons, with exclusively ipsilateral stimulation in $9 \%$ of neurons, and with stimulation of either pathway in $31 \%$ of neurons (Fig. 1). The remaining $11 \%$ of neurons failed to exhibit synaptic inhibition. In the majority of cells, the synaptically evoked excitatory postsynaptic potentials (EPSPs) were able to trigger an action potential (AP) at sufficient stimulus levels. This occurred in $81 \%$ of MSO neurons to ipsilateral stimulation and in $65 \%$ of MSO neurons to contralateral stimulation. In four neurons, it was necessary to coactivate both pathways to elicit an AP.

The effect of synaptic inhibition was level dependent in all cells, increasing with greater stimulus voltages ( Fig. $2 A$ ). In $94 \%$ of MSO neurons, the APs were blocked as stimulus amplitude was increased (Fig. $2 B$ ). In a few extreme cases, the AP amplitude appeared to gradually decrease until it was completely suppressed (Fig. $2 C$ ). In experiments using monolateral stimulation, the inhibitory postsynaptic potentials (IPSPs) that were recruited at higher stimulus levels were often sufficient to suppress an AP. This was true for $60 \%$ of neurons tested with ipsilateral stimulation and $82 \%$ of neurons tested with contralateral stimulation. In the neurons receiving synaptic inhibition exclusively from the contralateral side, the IPSPs were strong enough to block even bilaterally evoked action potentials in $85 \%$ of the cases. In the five neurons exhibiting exclusively ipsilateral inhibition, the bilaterally evoked AP could be blocked by increasing stimulus level in only one case.

The inhibitory effects mediated by each pathway usually summated, resulting in lower stimulus amplitudes necessary to block the AP. In two of four neurons with bilateral inhibition, where monolateral stimuli were insufficient to block the AP, bilateral stimulation did suppress the AP.

The synaptically evoked APs displayed relatively small $(<0.25 \mathrm{~ms})$ latency shifts with increasing stimulus amplitudes in $56 \%$ of neurons, but exhibited a rather dramatic latency decrease ( $\leq 2 \mathrm{~ms}$ ) in $44 \%$ of neurons (Fig. $2 \mathrm{~B}$ ). The latency shift was independent of the inhibitory inputs. For example, within the group of neurons that did not exhibit any IPSPs, three of seven neurons revealed prominent latency shifts.

In most neurons $(81 \%)$, the apparent refractory period that followed a synaptically evoked AP was prolonged as stimulus amplitude increased (Fig. $2 D$ ), presumably because of the recruitment of inhibition. The addition of a glycine receptor antagonist, strychnine $(50 \mathrm{mM}, 200 \mu \mathrm{l})$, shortened the apparent refractory period for a given stimulus level in three of five neurons tested.

The inhibitory transmitter glycine $(100 \mathrm{mM}, 5-50 \mu \mathrm{l})$ completely suppressed EPSPs and synaptically evoked APs in 28 of 32 neurons tested (Fig. $3 A$ ). The synaptically evoked APs that were blocked by IPSPs at high stimulus levels reemerged in the presence of strychnine in 9 of 10 neurons (Fig. $3 B$ ). The APs were again suppressed as the strychnine was eliminated from the brain slice. In contrast, the inhibitory transmitter GABA $(100 \mathrm{mM}, 20-100 \mu \mathrm{l})$, had no effect on AP amplitude in 17 of $18 \mathrm{MSO}$ neurons. In a single cell, GABA completely blocked all EPSPs and APs, as did glycine.

\section{DISCUSSION}

The main result of this study was that most MSO neurons displayed synaptic inhibition after stimulation of one or both afferent pathways. Furthermore, the neurotransmitter that mimicked synaptic inhibition was found to be glycine. These results are consistent with anatomic and immunohistochemical studies from other laboratories (Adams and Mugnaini 1990; Cant and Hyson 1992; Glendenning and Baker 1988; Kuwabara and Zook 1991; Spangler et al. 1985; Wenthold et al. 1987), as well as the observations of out-of-phase inhibition in the superior olive (Goldberg and Brown 1969; Yin and Chan 1990).

The results are also consistent with the neuropharmacological results obtained in vivo within the mustached bat's MSO. In this system, the contralateral glycinergic projec- 


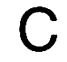

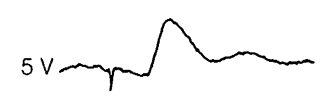
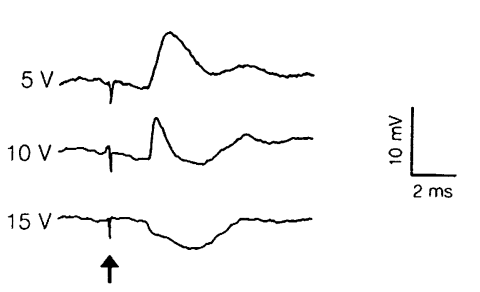

B

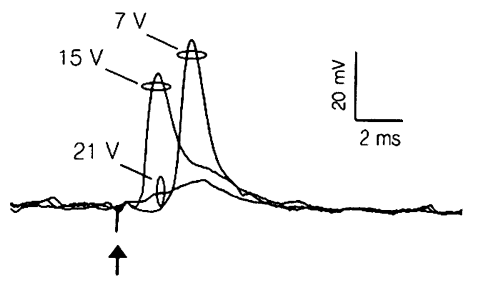

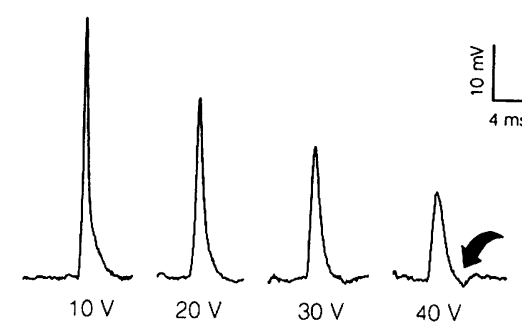

D

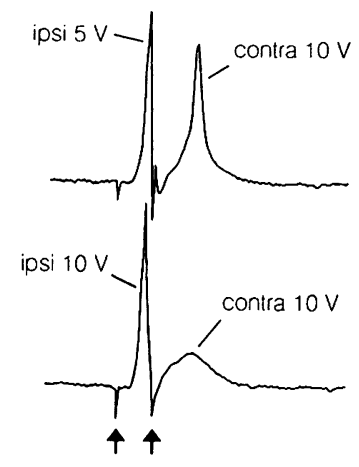

FIG. 2. Stimulus-evoked inhibition in the medial superior olive (MSO). $A$ : example of the interaction of an excitatory postsynaptic potential (EPSP) and an inhibitory postsynaptic potential (IPSP) in an MSO neuron, evoked by stimulation of the ipsilateral pathway. As shown in the 3 traces, the IPSP was enhanced with increasing stimulus amplitude. Arrow, stimulus artifact. Resting potential, $-56 \mathrm{mV}$. $B$ : effect of increasing stimulus amplitude on action potential (AP) latency and inhibition. An increase of stimulus amplitude first led to an AP latency decrease of $1.8 \mathrm{~ms}$. As stimulus amplitude was increased further, the AP was completely suppressed. Arrow, stimulus artifact. Resting potential, $-48 \mathrm{mV}$. $C$ : example of the attenuation of an AP by increasing stimulus amplitude. The 4 traces show the recruitment of synaptic inhibition as stimulus amplitude was raised from 10 to $40 \mathrm{~V}$ (contralateral stimulation only). A hyperpolarizing transient becomes evident at $40 \mathrm{~V}(-)$. Resting potential, $-54 \mathrm{mV}$. $D$ : in some neurons, the apparent refractory period was prolonged at greater stimulus amplitudes. In the top trace, the ipsilateral stimulus (1 st arrow) was $5 \mathrm{~V}$ and evoked an AP. The contralateral stimulus ( $10 \mathrm{~V}$ ) was delayed and also evoked an AP. In the bottom trace, the $1 \mathrm{st}$ stimulus was increased to $10 \mathrm{~V}$, whereas the 2 nd stimulus remained unchanged. The more intense 1st stimulus prolonged the period during which contralaterally evoked APs were suppressed. Arrow, stimulus artifact. Resting potential, $-54 \mathrm{mV}$. tion contours the sustained neuronal responses to pure tones into phasic responses, depending on its relative timing to the contralateral excitatory projection (Grothe 1990; Grothe et al. 1992).

The present results revealed that inhibition was dependent on the stimulus amplitude delivered to either afferent pathway. There was a dramatic enhancement of synaptic inhibition as stimulus voltage was raised. This finding is consistent with the stimulus level dependence of inhibition in the dorsal cochlear nucleus (Hirsch and Oertel 1988). This was best demonstrated by the fact that APs could always be elicited at lower stimulus amplitudes from those that recruited synaptic inhibition (Fig. 2, $B$ and $C$ ). A hyperpolarizing potential was not always evident at those stimulus levels where the AP was blocked. Given the placement of our stimulating electrodes (see METHODS), it is likely that excitatory fibers of passage were activated first, followed by synaptic recruitment of the glycinergic projections from the MNTB or LNTB (Cant and Hyson 1992; Kuwabara and Zook 1991).

Synaptic inhibition prolonged the apparent refractory period that followed an evoked AP (Fig. $2 D$ ). The prolongation occurred for stimulus amplitudes greater than those that produced shifts of the AP latency. The probability that a second AP can be triggered (in response to a 2nd EPSP) with a short latency relative to the first AP will impact on the precise coding of time patterns over tens of milliseconds by MSO neurons.

Glycine was able to mimic the effect of ipsilateral and contralateral synaptic inhibition in most neurons (Fig. $3 A$ ). This was evidenced by a decrement in the synaptically evoked AP amplitude in the presence of glycine. The effect of the glycine receptor antagonist strychnine was consistent with this finding. Strychnine reversed the effects of synaptic inhibition such that APs could be evoked in its presence regardless of stimulus intensity (Fig. $3 B$ ).

Stimulus-evoked inhibition usually blocked the AP without first decreasing its amplitude. However, stimulusevoked inhibition, glycine, or strychnine sometimes led to an attenuated AP amplitude before full suppression (Figs. $2 C$ and $3 B$ ). This phenomenon has apparently been observed previously, but the mechanism remains obscure (Curtis et al. 1968; Krnević et al. 1966; Werman et al. 1968; Wu and Kelly 1992). For example, Curtis et al. (1968) have noted that the amplitude of extracellularly recorded APs decreased in the presence of glycine. Presumably, glycine-gated $\mathrm{Cl}^{-}$channels lower the input resistance of the neuron at the recording site, thereby decreasing the size of the evoked AP (Coombs et al. 1955; Curtis and Eccles 1959 ). If the AP is generated at a site that is electrotonically distant from our recording electrode and the glycinergic synapses, as suggested by Yin and Chan (1990), the inhibitory synaptic currents may be attenuating a passively conducted signal. It should be noted that a role for attenuated action potentials has been considered previously (Lorente de Nó and Condouris 1959).

That GABA blocked an AP in one neuron is consistent with immunocytochemical data showing sparse GABAergic terminals within the MSO (Adams and Mugnaini 1990). However, GABAergic inhibition was much less prominent than would be expected from the GAD immunocytochemical staining pattern in gerbils (Roberts and $\mathrm{Ri}$ bak 1987). Our results are more consistent with in vivo pharmacological results from the mustache bat's MSO, where GABA failed to have an effect during sound stimulation (Grothe 1990). 


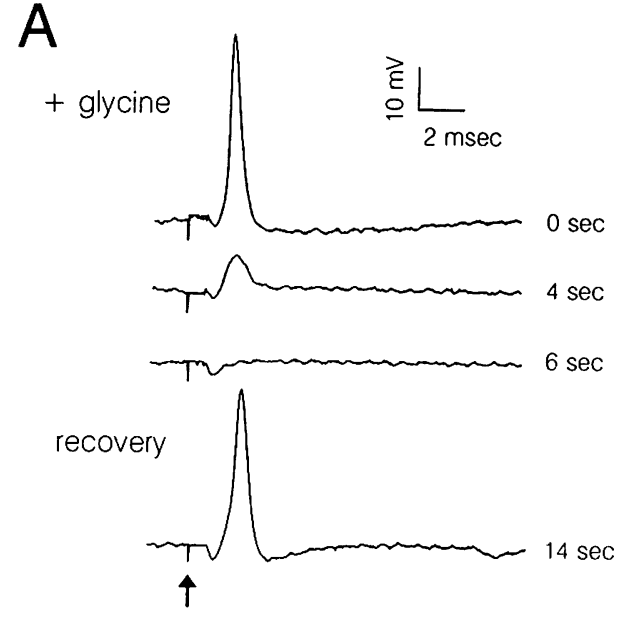

B

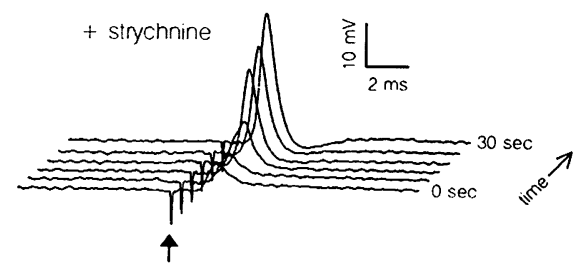

FIG. 3. Pharmacology of the inhibitory response. $A$ : glycine completely blocked excitatory postsynaptic potentials (EPSPs) and action potentials (APs) in most cells. Top: control trace. Middle: in the presence of glycine, the AP is blocked $(100 \mathrm{mM} ; 20 \mu \mathrm{l})$. Bottom: after recovery for 1 min. Arrow, stimulus artifact. Resting potential, $-62 \mathrm{mV}$. $B$ : bilateral stimulation with $30 \mathrm{~V}$ ipsilateral and $25 \mathrm{~V}$ contralateral resulted in a weak EPSP only (bollom line). In the presence of strychnine $(50 \mathrm{mM}, 200 \mu \mathrm{l})$, an AP gradually emerged. The effect was fully reversible. Arrow, stimulus artifact. Resting potential, $-54 \mathrm{mV}$.

The present results demonstrate that stimulus coding by MSO neurons involves the integration of a fairly powerful synaptic inhibition. This suggests that coincidence-detection of EPSPs may be an incomplete model of time difference coding in mammals. However, it is possible that excitatory convergence alone may account for ITD coding in avian species (Carr and Konishi 1990; Overholt et al. 1992; Sullivan and Konishi 1986). In mammals, it appears that a convergence of binaural inhibition is superimposed on the well-studied binaural excitatory pathway. Our results indicate that synaptic inhibition is recruited at greater stimulus levels. Therefore, binaural inhibition may lead to discrete activity patterns across the MSO population when excitatory drive is maximal. Finally, we must remain open to the possibility that inhibition subserves a role unrelated to ITD coding in the MSO, as is true in the bat (Grothe et al. 1992). We are currently determining the effect that glycinergic transmission has on bilateral time difference coding in vitro.

We gratefully acknowledge M.-L. Liou for expert design of the automated stimulation and acquisition software. We thank both anonymous reviewers for their thoughtful questions.

This work was supported by National Institute of Deafness and Other
Communicative Disorders Grant DC-00540 and Deutsche Forschungsgemeinschaft.

Address for reprint requests: D. H. Sanes, Center for Neural Science, 6 Washington Place, New York University, New York, NY 10003.

Received 18 September 1992; accepted in final form 4 December 1992.

\section{REFERENCES}

ADAMS, J. C. AND MUGNAINI, E. Immunohistochemical evidence for inhibitory and disinhibitory circuits in the superior olive. Hear. Res. 49: 281-298, 1990.

CAIRD, D. AND KLINKE, R. Processing of binaural stimuli by cat superior olivary complex neurons. Exp. Brain Res. 52: 385-399, 1983.

CANT, N. B. AND HysON, R. L. Projections from the lateral nucleus of the trapezoid body to the medial olivary nucleus in the gerbil. Hear. Res. 58: 26-34, 1992.

CARR, C. E. AND KoNISHI, M. A circuit for detection of interaural time differences in the brain stem of the barn owl. J. Neurosci. 10: 32273246, 1990.

Casseday, J. H. AND NefF, W. D. Localization of pure tones. J. Acoust. Soc. Am. 54: 365-372, 1973.

CLARK, G. M. Vesicle shape versus synapse in the nerve endings in the cat medial superior olive. Brain Res. 15: 548-551, 1969.

Colburn, H. S., HaN, Y.-A., AND CulOtTA, C. P. Coincidence model of MSO responses. Hear. Res. 49: 335-346, 1990.

COOMBS, J. S., ECCLES, J. C., AND FATT, P. The inhibitory suppression of reflex discharges from motoneurones. J. Physiol. Lond. 130: 396-413, 1955.

COVEY, E., VATER, M., AND CASSEDAY, J. H. Binaural properties of single units in the superior olivary complex of the mustache bat. J. Neurophysiol. 66: 1080-1094, 1991.

CURTIS, D. R. AND ECCLES, J. C. The time courses of excitatory and inhibitory synaptic actions. J. Physiol. Lond. 145: 529-546, 1959.

CuRTIS, D. R., HösLI, L., AND Johnston, G. A. R. A pharmacological study of the depression of spinal neurons by glycine and related amino acids. Exp. Brain Res. 6: 1-18, 1968.

GOLDBERG, J. M. AND BROWN, P. B. Functional organization of the dog superior olivary complex: an anatomical and electrophysiological study. J. Neurophysiol. 31: 639-656, 1968.

GOLDBERG, J. M. AND BROWN, P. B. Response of binaural neurons of the dog superior olivary complex to dichotic tonal stimuli: some physiological mechanisms of sound localization. J. Neurophysiol. 32: 613-636, 1969.

GLENDENNING, K. K. AND BAKER, B. N. Neuroanatomical distribution of receptors for three potential inhibitory neurotransmitters in the brainstem auditory nuclei of the cat. J. Comp. Neurol. 275: 288-308, 1988.

GRoTHE, B. Versuch einer Definition des medialen Kernes des oberen Olivenkomplexes bei der Neuweltfledermaus Pteronotus p. parnellii ( $\mathrm{PhD}$ dissertation). Munich, FRG: Ludwig-Maximilians-Universitaet München, 1990.

Grothe, B., Vater, M., Casseday, J. H., AND Covey, E. Monaural interaction of excitation and inhibition in the medial superior olive of the mustached bat: an adaptation for biosonar. Proc. Natl. Acad. Sci. USA 89: 5108-5112, 1992.

HALL, J, L. Binaural interaction in the accessory superior olivary nucleus in the cat. Int. J. Neurosci. 4: 147-166, 1965.

HARNishfeger, G., NeuWeiler, G., AND SCHLEGEl, P. Interaural time and intensity coding in superior olivary complex and inferior colliculus of the echolocating bat Molossus ater. J. Neurophysiol. 53: 89-109, 1985.

HiRSCH, J. A. AND OERTEL, D. Synaptic connections in the dorsal cochlear nucleus of mice, in vitro. J. Physiol. Lond. 396: 549-562, 1988.

HodGKIN, A. L. AND HuXLEY, A. F. The dual effect of membrane potential on sodium conductance in the giant axon of Loligo. J. Physiol. Lond. 116: 497-506, 1952.

JEFFRESS, L. A. A place theory of sound localization. J. Comp. Psychol. 41 : 35-39, 1948.

JENKINS, W. M. AND MASTERTON, R. B. Sound localization: effects of unilateral lesions in central auditory system. J. Neurophysiol. 47: 9871016, 1982.

Krnević, K., Randić, M., and Straughan, D. W. Pharmacology of cortical inhibition. J. Physiol. Lond. 184: 78-105, 1966.

KUWABARA, N. AND ZOOK, J. M. Classification of the principal cells of the 
medial nucleus of the trapezoid body. J. Comp. Neurol. 314: 707-720, 1991.

LANGFORD, T. L. Responses elicited from medial superior olivary neurons by stimuli associated with binaural masking and unmasking. Hear. Res. 15: 39-50, 1984

LORENTE DE Nó, R. AND CONDOURIS, G. A. Decremental conduction in peripheral nerve. Integration of stimuli in the neuron. Proc. Natl. Acad. Sci. USA 45: 592-617, 1959.

MOORE, M. J. AND CASPaRY, D. M. Strychnine blocks binaural inhibition in lateral superior olivary complex. J. Neurosci. 3: 237-242, 1983.

OVERHOLDT, E. M., RUBEL, E. W., AND HYSON, R. L. A circuit for interaural time differences in the chick brainstem. J. Neurosci. 12: 1698$1708,1992$.

PERKINS, R. E. An electron microscopy study of synaptic organization in the medial superior olive of normal and experimental chinchillas. $J$. Comp. Neurol. 148: 387-416, 1973.

ROBERTS. R. C. AND RIBAK, C. E. GABAergic neurons and axon terminals in the brainstem auditory nuclei of the gerbil. J. Comp. Neurol. 258: 267-280, 1987.

Rose, J. E., Gross, N. B., Geisler, C. D., AND Hind, J. E. Some neural mechanisms in the inferior colliculus in the cat which may be relevant to localization of a sound source. J. Neurophysiol. 29: 288-314, 1966.

SANES, D. H. An in vitro analysis of sound localization mechanisms in the gerbil lateral superior olive. J. Neurosci. 10: 3494-3506, 1990.
Sanes, D. H., Geary, W. A., Wooten, G. F., and Rubel, E. W. Quantitative distribution of the glycine receptor in the auditory brain stem of the gerbil. J. Neurosci. 7: 3793-3802, 1987.

SPANGLER, K. M., WARR, W. B., AND HeNKel, C. K. The projections of principal cells of the medial nucleus of the trapezoid body in the cat. $J$. Comp. Neurol. 238: 249-262, 1985.

STOTLER, W. A. An experimental study of the cells and connections of the superior olivary complex of the cat. J. Comp. Neurol. 98: 401-432. 1953.

Sullivan, W. E. AND KoNishi, M. Neuronal map of interaural phase differences in the owl's brainstem. Proc. Natl. Acad. Sci. USA 83: 84008404,1986

WARR, W. B. Fiber degeneration following lesions in the anterior ventral cochlear nucleus of the cat. Exp. Neurol. 14: 453-474, 1966.

Wenthold, L. P., Huie, D., Altschuler, R. A., AND Reeks, K. A. Glycine immunoreactivity localized in the cochlear nucleus and the superior olivary complex. Neuroscience 22: 897-912, 1987.

WERMAN, R., DAVIDOFF, R. A., AND APRISON, M. H. Inhibitory action of glycine on spinal neurons in the cat. J. Neurophysiol. 31: 81-95, 1968.

WU, S. H. AND KelLY, J. B. Synaptic pharmacology of the superior olivary complex studied in the mouse brain slice. J. Neurosci. 12: 3084-3097. 1992

YIN, T. C. T. AND Chan, J. C. K. Interaural time sensitivity in medial superior olive of cat. J. Neurophysiol. 64: 465-488, 1990. 